\title{
Fostering diffusion of scientific contents of National Society Cardiovascular Journals: the new ESC search engine
}

\author{
F. Alfonso • L. Gonçalves $\cdot$ F. Pinto • A. Timmis $\cdot$ H. Ector $\cdot$ \\ G. Ambrosio • P. Vardas • On behalf of the Editors' \\ Network European Society of Cardiology Task Force
}

Published online: 27 September 2013

(C) The Author(s) 2013. This article is published with open access at Springerlink.com

\begin{abstract}
European Society of Cardiology (ESC) National Society Cardiovascular Journals (NSCJs) are high-quality biomedical journals focused on cardiovascular diseases. The Editors' Network of the ESC devises editorial initiatives aimed at improving the scientific quality and diffusion of NSCJ. In this article we will discuss on the importance of the Internet, electronic editions and open access strategies on scientific publishing. Finally, we will propose a new editorial initiative based on a novel electronic tool on the ESC webpage that may further help to increase the dissemination of contents and visibility of NSCJs.
\end{abstract}

Keywords Biomedical journal · Editors network ·

Open access $\cdot$ Internet $\cdot$ Electronic editions

The National Society Cardiovascular Journals (NSCJs) of the European Society of Cardiology (ESC) are high-quality biomedical journals devoted to publishing original research and educative material on cardiovascular diseases [1-3]. These journals officially belong to the corresponding ESC National

Editors' Network Members (Editors-in-Chiefs of National Society Cardiovascular Journals):

F. Alfonso • F. Pinto • A. Timmis • H. Ector · G. Ambrosio •

P. Vardas

Network of the European, Society of Cardiology, Madrid, Spain

F. Alfonso

ESC Editors' Network Task Force Chair, Madrid, Spain

L. Gonçalves

ESC Search Engine Task Force Chair, Madrid, Spain

F. Alfonso $(\square)$

Interventional Cardiology, Cardiovascular Institute,

Clínico San Carlos University Hospital, IdISSC, Plaza Cristo Rey,

Madrid 28040, Spain

e-mail: falf@hotmail.com
Cardiac Societies. Many of them have achieved major international recognition, are included in most important bibliometric databases, and have made major scientific impact [1-5]. Some NSCJs offer full-text English content and are freely available in electronic editions. However, NSCJs are largely heterogeneous and some of them are only published in local languages with a limited visibility [1-3].

The main goal of biomedical journals is to publish highquality scientific information. To achieve this goal, journals should compete for the best research carried out in their field, the 'prestige' of the journal being the main driver to attract original contributions [1-3]. In turn, a journal's prestige is based on credibility, diffusion and scientific impact [6]. To ensure that the scientific process is fully respected, journals rely in the 'peer review' system. This process not only allows the editors to select the best possible material for publication, but also assures the readers that the quality of the information follows the highest scientific standards. In fact, the process significantly improves the final quality of manuscripts eventually published. Once an article is definitely accepted for publication, the journal should guarantee its expedited publication and widespread diffusion among the scientific community [1-3].

The Editors' Network of the ESC provides a unique platform for devising editorial initiatives aimed to improve the scientific quality, and facilitate diffusion of the contents of NSCJs [1-5]. Herein we will discuss the importance of the internet and electronic editions in scientific publishing. We will also review the growing relevance of open access $(\mathrm{OA})$ strategies. Last but not least, we will propose a new initiative based on a novel electronic tool that may further help to increase the diffusion, dissemination and overall visibility of NSCJs. This tool, located on the ESC website, should foster collaboration among the different NSCJs and also broaden exposure from diverse scientific sites and ESC official journals. Hopefully, this will help to further expand the scientific impact of European cardiovascular research. 


\section{Electronic editions and the internet: a paradigm shift in scientific publishing}

Sharing the results of late breaking research through peerreviewed journals remains the mainstay of the scientific process and progress in science [1-3]. The success of research requires articles to be read, spread, discussed and cited by interested investigators. Therefore, in the fast moving and globalised world of science, journals should ensure maximal accessibility and diffusion of their articles [1-3]. Indeed, most publications have already moved into a new 'online era' where the emphasis is placed on the internet and electronic editions [1-3]. Just a few years ago, scholars did all their reading in paper journal issues obtained as personal copies circulating within their organisations, or by retrieving issues from library archives [7]. Today the predominant reading mode is to download a digital copy and either read it directly on the screen or as a printout [7]. Currently, readers and investigators readily retrieve articles with just a click on their home or office computers [7].

Interestingly, the internet not only affects research but also clinical practice. Nowadays, physicians are often approached and challenged by patients who have downloaded medical information from the internet. Often they face either unnecessarily worried patients or patients with unrealistic expectations. Although some patients are confused, others are overinformed and demand in-depth explanations regarding their diagnosis, management and prognosis. Patient-oriented information should be provided by scientific societies to address these demands. Therefore, even everyday clinical practice should accommodate the sociocultural change induced by the internet.

Access to medical information has been revolutionised by electronic editions. Likewise, bibliometric databases are also evolving. Medline, the ISI Web of Science and, more recently, Scopus offer comprehensive online information on medical literature [8-11]. In addition, Google Scholar is increasingly used by many investigators [8-11]. Scopus and, especially, Google Scholar obtain data from larger data sources including widely diverse scientific items (not only ISI publications) and therefore offer a slightly different perspective on the field. Interestingly, Google Scholar is free, and various studies suggest that it provides accurate search and data analyses that differ little from those obtained from classical bibliometric sources [8-11].

Traditionally, the most commonly used source of bibliometric data is the Thomson ISI Web of Knowledge, in particular the Science Citation Index and the Journal Citation Reports, which provide the yearly journal Impact Factors. Recently, other indicators such as SCImago scientific journal rank (SJR) and the Eigenfactor have emerged as alternative indices of a journal's quality [8-11]. These consider not only the number but also the 'quality' or relevance of the citations received by a given paper. Quantitative publication metrics (research output) and citation analyses (scientific influence) are key determinants of the scientific success of individual investigators and institutions because the 'publish or perish' dictum still prevails in most academic settings [8-11]. In this scenario, electronic editions and accessibility on the internet certainly play a critical role. Nowadays, once a paper is electronically published on a journal website, the information can propagate rapidly in the community, and extremely high downloads could be the result of mechanisms such as the 'Matthew effect' (richer get richer) [12]. Indeed, the relationship between the number of citations acquired by an article and the number of downloads has been explored [13]. Hit counts on a journal website for an article during the week after its online publication predict the number of citations of that article in subsequent years [14]. Of note, Uniform Resource Locators (URLs) are being increasingly used in scientific publications [15]. Citation of URLs provides the possibility of calculating an objective electronic Impact Factor (eIF) to measure their impact on scientific research [15]. However, the stability of URLs remains a matter of concern, and this should be guaranteed by the responsible organisation because URLs are vulnerable to technical problems and may become inaccessible in a time-dependent manner [15].

Notably, the internet offers a new window into science and provides new insights on access and use of research [16]. Currently, web-usage data can be analysed in depth to outline a 'map of knowledge'. According to Butler [16], when readers click from one page to another while looking through online scientific journals, they generate a chain of connections between links they think belong together. These 'click- stream events' may be analysed to map such connections and to provide a snapshot of interconnections between disciplines. Usage maps reveal how often users looking at an article in journal A moved on to an article in journal B during a browser session. By aggregating all these complex relationships using network-visualisation algorithms, maps can be generated based on the 'distances' between journals and disciplines [16]. The structure of these maps is quite similar to those created using citation data: a network of clusters in different fields within which journals have strong connections with one another but fewer links to other clusters. Interestingly, journals in the humanities and social sciences figure much more prominently in these maps than in citation-based maps [16]. Another key difference between citation- and usage-based maps is that the former only reflect citations by researchers who publish, and ignore the impact of papers on the medical community who read and apply the literature in medical practice but who rarely publish. Citation data may undervalue papers written in practitioner-based fields that are widely read but not cited proportionally [16]. Moreover, usage maps are more up-to-date than citation ones because of the inherent delay in publication, therefore providing a different time slice 
of the scientific process. Accordingly, both usage and citation data each provide complementary information on the impact of papers and journals on the scientific community [16].

Electronic editions provide unique publishing possibilities and open up new venues in scientific communication [1-3]. For instance, they offer a flexible layout and structure for articles, new formats and the possibility of including additional documentation attached to the paper as media enhancements (videos, etc.). Important sections such as methods and additional data can be now presented as supplementary material without additional cost. Electronic managing systems facilitate both the processes of peer review and publishing [1-3]. Open peer review and even post-publication readers' comments can be uploaded on the journal website, facilitating interactivity and a more transparent and dynamic scientific process. Finally, statistics on electronic papers (downloads and Citation metrics) are offered for the interest of readers and researchers [17].

Publicly available data are advocated as a means to further promote transparency in research and more open science [18-20]. Online editions allow the publication of longer papers free from the economic burden of print charges. Posting the complete anonymised 'raw dataset' has been advocated in this regard [18-20]. The raw data can be used to confirm original results by independent analyses and also to explore related or new hypotheses, particularly when combined with other publicly avail- able datasets. From an ethical perspective, it appears unacceptable that, while patients are willing to share data about themselves with investigators and sponsors, the latter may be unwilling to share the trial data with others. Data sharing among genomic investigators has already been successful. However, this strategy may cause concerns such as inappropriate analyses, 'data dredging' and drawing inappropriate conclusions [18-20]. The International Committee of Medical Journal Editors has developed guidelines for the preparation of raw clinical data for publication [18]. Interestingly, this practice has been associated with a $69 \%$ increase in citations, independently of journal Impact Factor, date of publication and author country of origin [20]. The correlation between publicly available data and increased literature impact may further motivate investigators to share their detailed research data.

On the other hand, Web 2.0 has also been increasingly used in the medical field [21-25]. RSS feeds, podcasts, personal publishing platforms (blogs), social networks (such as Twitter and Facebook) and social media are proposed as innovative tools for educating and updating clinicians. They allow physicians to distribute, share and comment on medical information [21-25]. However, the scientific community is less than eager to regard them as equivalent to the traditional models of information dissemination in peer-reviewed medical journals. In this regard, some have proposed that platforms of postpublication peer review may provide the required safeguard in this new setting [22]. In addition, intuitive browsing of journal content on smart- phones and the iPad is being provided by a growing number of publications (including the European Heart Journal) [24, 25] to enhance diffusion of contents [21]. Furthermore, some Web 2.0 technologies facilitate collaborative data collection for clinical trials [23]. Google Docs, for instance, is freely available and allows multiple users to enter patient data into electronic case report forms of multicentre trials through mobile devices [23].

Finally, we should keep in mind that English represents the 'lingua franca' of science. This is important, and efforts should be made within the ESC to prevent tower-of-Babel phenomena in the digital era [1-3]. However, this may create major problems and unique challenges for non- English-speaking investigators and countries [26]. In fact, some NSCJs only publish in their mother tongue and are therefore not readily accessible to the international scientific community. Some NSCJs have decided to publish their articles in both their native language and English, to address healthcare professionals and international scholars, respectively. Difficult concepts are easier to remember in the mother tongue. Interestingly, Public Library of Science journals encourage non-English-speaking authors to provide a version of their article in their original language as supporting material [27]. Science should not be considered an 'ivory tower' separated from the rest of society, but rather imbedded in it to facilitate its cultural assimilation [27].

\section{Some editorial perspectives on 'open access' initiatives}

The internet and electronic editions set the basis for OA initiatives $[28,29]$. The two main characteristics of OA publications are: (1) all published contents are freely accessible through the internet; (2) readers are given copyright permission as long as authors and publishers receive adequate attribution [28]. In turn, this model requires two major changes from the traditional subscription-based model. First, OA shifts the financing of publication from readers (subscription fees from individuals or universities) to authors and investigators (through the corresponding funding organisation or academic institutions) by means of article-processing fees [28]. Second, the copyright is no longer used to prevent, but rather to stimulate, republication. Subscription-based journals usually require authors to transfer the copyright to the journal so that they are empowered to restrict access to paying customers and threaten competing publications with infringement lawsuits. Major subscription-based journals are partly financed by individuals and medical societies but mainly by bundled elicense agreements between publishers and universities or librarians [28, 29]. Individual electronic articles can also be accessed on a pay-per-view basis. Readers are charged one way or the other in the traditional way, whereas authors and investigators are charged in the OA model $[28,29]$. Some commercial publishers charge authors a publication fee to substitute for subscription revenue while significantly limiting 
reuse. These initiatives, however, should not be considered real OA. Some traditional publishers have recently instituted 'hybrid' initiatives where authors are allowed (after paying a fee) to make individual articles OA $[28,29]$.

In the early 90 s, pioneer OA journals were founded by individual investigators based on voluntary work and were usually hosted in individual or university servers [29]. Thereafter, many established journals made their articles OA when they implemented their digital editions in parallel with print editions. This was especially the case for official journals of medical societies and in non-English-speaking countries in an attempt to increase their readership and impact [30]. In the last decade, new, formal, OA journals have flourished using articleprocessing charges to finance publications [29]. Interestingly, some major publishers (BioMed Central, Public Library of Science) have specialised in OA [29]. OA has two major pathways: 'gold' OA (via direct publishing) and 'green' OA (traditional publication in subscription-based journals with parallel open posting of the final manuscript on the web). Green $\mathrm{OA}$ is delivered by repositories, whereas gold OA is delivered by journals [31]. Licences range from any kind of reuse provided that proper attribution is made (CC-BY) to those that limit commercial use (CC-BY-NC) [31].

The health of the free-access author-pay model can be demonstrated by data showing the steady growth of papers published in OA journals (20\% per year) and also in the number of OA journals (15\% per year), either as new journals or traditional journals switching to this model [32]. Currently, $30 \%$ of all peer-review journals in the world are OA [31].

OA benefits science by accelerating dissemination and uptake of research findings. A major advantage of $\mathrm{OA}$ is that readers can use any web-based research tool to access and review the literature [28]. These articles are quickly recognised and their results are readily picked up and discussed by peers [33]. As already mentioned, there are two main modalities of OA: OA journals and self-archiving. Interestingly, some studies suggest that articles immediately published as OA on the journal site (gold route) have higher impact than self-archived or otherwise openly accessible OA articles (green route) [33].

Overall OA initiatives increase diffusion of content, citations and eventually the Impact Factor of the corresponding journals [33-35]. Early studies analysed the effect of 'online status' on the Impact Factor of biomedical journals [36]. They found that providing online access with 'full text on the net' increases the visibility of a journal [36]. In addition, the presence of journals on Medline as 'full text on the net' also boosts their Impact Factor [37]. This bias is explained by the tendency to peruse what is more readily available [37]. OA initiatives also appear to increase the Impact Factor [33-35]. However, some argue that this effect may confound between open and electronic access. Nevertheless, recent reports suggest that, in most developed countries, journal articles receive an increase in citations when they come online freely, but experience an additional jump when they first come online through commercial sources [35]. This effect appears to be reversed in poor countries, where free-access articles are much more likely to be cited [35]. All together, these findings suggest that free internet access widens the circle of those who read and make use of scientific research. In addition, this 'OA impact advantage' does not appear to be a 'quality bias' from authors self- selecting what to make OA, because some studies suggest that this advance persists after adjustment for many other potential confounders related to the editorial and research quality [38].

Interestingly, a randomised trial on $\mathrm{OA}$ publishing analysed the effects of free access on article downloads and citations [39]. Articles placed in the OA condition received significantly more downloads and reached a broader audience within the first year. However, in this particular study, OA articles were cited no more frequently, nor earlier, than subscription-access articles within 3 years. It was suggested that the process of 'social stratification', accounting for a concentration of scientific authors at a small number of elite research universities with excellent access to the scientific literature, might help to explain this apparent paradox [39]. Moreover, this controlled study suggests that the real beneficiaries of OA publishing may not be the research community but rather communities of medical practice that consume, but rarely contribute to, the corpus of literature [39].

As discussed, embargoes are currently imposed by publishers for economic reasons. This may be a significant barrier to access in biomedical sciences. As previously emphasised, it has been suggested that users favour electronic access and often eschew articles that are not available electronically [40]. In a shy attempt to tackle these problems, many journals now offer free access to all articles 6 months after publication and welcome the publication of articles as OA after a fee is paid by the authors.

However, research funding bodies are becoming increasingly sensible to this ethical issue. Many would argue that it is unethical to use the research grants from government (people's money) and not allow the scientific community to have free access to the results of the study. To address such issues, the Berlin Declaration suggested the establishment of OA repositories. All investigators who have received public grants should submit the full text of the paper published from their study to PubMed Central and also ensure self- archiving at the corresponding university or research institution. Obviously, OA journals provide an attractive solution to the problem of restricted access to results of publicly funded research [41].

Most countries and founding bodies are currently taking further actions to ensure OA for publicly funded research [41-43]. Researchers are compelled to make their work publicly available in repositories (green road) within 12 months of publication. Other bodies even suggest that authors should make their work free by the publisher upfront (gold road). Clearly, research budgets should be reallocated with this aim, although the logistics required and the implications of this 
change remain a matter of ongoing debate. In July 2012, a new OA policy was announced by the European Union that recommended OA policies for all member states [31, 41-43]. Hopefully, this will represent a paradigm shift in scientific publishing and will herald a new era of academic discovery.

\section{The ESC search engine}

In the last decade, the amount of documents and educational material available on ESC websites has increased exponentially. This situation has led to increasing difficulty for users to find the information they need. It has become obvious that a more comprehensive search solution is necessary. For this reason, the ESC decided to provide a better search experience for ESC site visitors http://www.escardio.org/about/corporatenews/Pages/Search-the-ESC.aspx. The ESC search engine uses semantic analysis to provide the best results from the keywords typed in http://www.escardio.org/about/welcome/ Pages/Search-the-ESC.aspx. This search engine project has four goals: (1) to provide a single entry point to multiple data sources (in fact, from a single entry point, the user will be able to explore an ESC-rich database of slides, scientific reports, guidelines, abstracts, clinical cases, news and articles from ESC journals); (2) to propose a tool that can treat requests expressed in natural language in a very user-friendly way; (3) to locate content that would be difficult to find or access otherwise, therefore saving precious time; (4) to allow visitors to find content by topic or person in an intuitive way.

In 2008, the ESC Board, chaired by Roberto Ferrari, decided to support the development of a semantic search engine that would be able to search for information on the ESC Central website and also on the websites of all six Associations (EHRA, EACVI [formerly EAE], EAPCI, HFA, EACPR, ACCA). This idea was based on the previously reported need to provide the user with a quick and easy way of obtaining information from hundreds of thousands of documents available on all these websites. Moreover, this engine is also looking into the ESC journals' family where it is possible to obtain results from more than 30,000 papers! Not surprisingly, this tool is a major success, already being the second most visited page of the ESC website, with 49,853 page views, in October and November of $2012 \mathrm{http}: / /$ snack.to/ fukiqkmc. With the help of this search engine, it is now extremely easy to obtain information by just typing in the keywords on the top right hand side of the screen inside the http://www.escardio.org landing page (Fig. 1). The result is a list of documents addressing that specific topic, and the user can select the ones required (Fig. 2).

This results page contains a lot of information and functionalities. Within the document preview, you can see how the document looks (Fig. 2). The relevance score assigned to this document is also displayed by the search engine. The type of document is also presented (guideline, abstract, slide presentation,

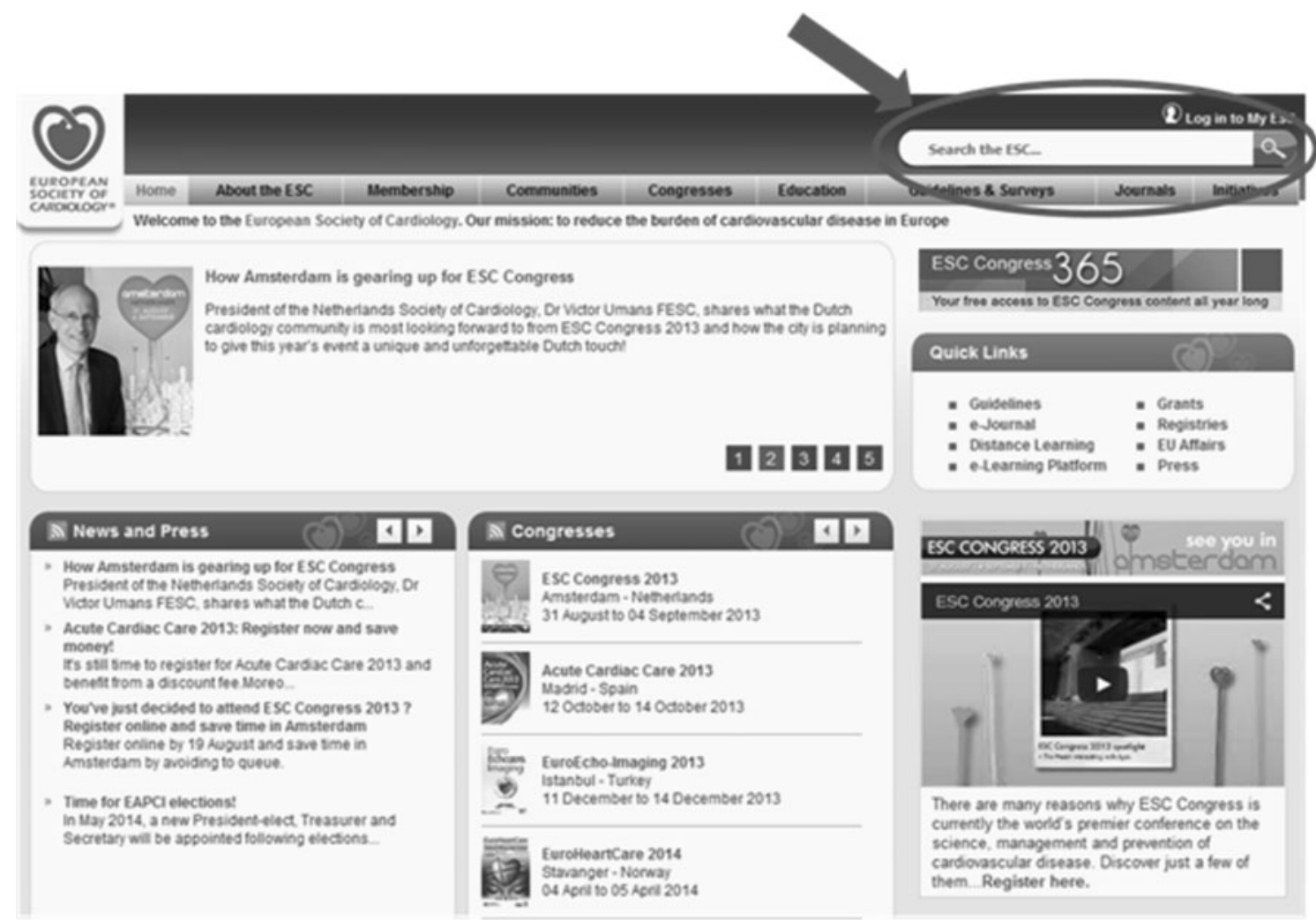

Fig. 1 European Society of Cardiology (ESC) website landing page. The search engine box is located at the top right hand side of the screen (arrow) 
scientific report, news, clinical case or a web document). The document origin can also be easily identified at a glance from a small institutional logo that can also be found on the results page, just below the icon showing the type of document. It is also important to know the document's availability. A padlock symbol is displayed when a document is behind a login so that you can still see that the resource exists, meaning that its access is for members only. This tool also allows the search to be refined by using filters located on the toolbar on the left. With this toolbar, the user can filter the type of document looked for (eg, only slides). It is also possible to filter only results from a given time period. During a congress, when a lot of content is published daily, the users can filter for what's new since the previous day, or only the results where a person is cited. Related terms are proposed by the engine from the keywords entered in the request to propose other related topics that could be of interest. If the same term is searched on a regular basis, the user may be interested in using the RSS feed functionality. Any search result page can be shown as an RSS feed which can be subscribed to, providing regular updates on what's new in the field.

\section{Time to involve the National Cardiac Societies' Journals!}

This project is already in its adulthood and the time has now come to enter into a second phase of development and also involve the NSCJs. The ESC Board under Michel Komajda's presidency decided to support the development of this project.
The ESC Editors' Network also gave an enthusiastic response and decided to contact those NSCJs that are already published in an electronic format and in English. Some of them already have a significant Impact Factor. The goal of this second phase of the project is to increase the visibility of the NSCJs and, as a consequence, to increase their readership and their level of reference in other international journals. Moreover, the excellent research that is performed at national level in many countries in Europe will become more visible worldwide.

This new tool is already available and, after typing in the keywords, the user gets two results: one from the ESC documents, and a second from the NSCJs. It will be possible for the user to see both in parallel and easily move from one result to the other with a simple click. The first NSCJs have been added to the search results and can now easily be identified and selected. The first five journals are: Revista Española de Cardiología, Heart and Blood Vessels (journal of the Cardiology Society of Serbia), Hellenic Journal of Cardiology, Egyptian Heart Journal and Romanian Journal of Cardiology. The Revista Portuguesa de Cardiologia is soon to be added. An arrangement has been made with the Brazilian Society of Cardiology, and its website is now including our search engine. This is an interesting way to raise awareness about this very useful tool and allow Brazilian cardiologists to have better access to our scientific resources. There is no doubt that providing this tool will strengthen even further the bonds between the ESC Central and the National Cardiac Societies, and European cardiovascular science will become more visible and readily accessible from any place in the world.

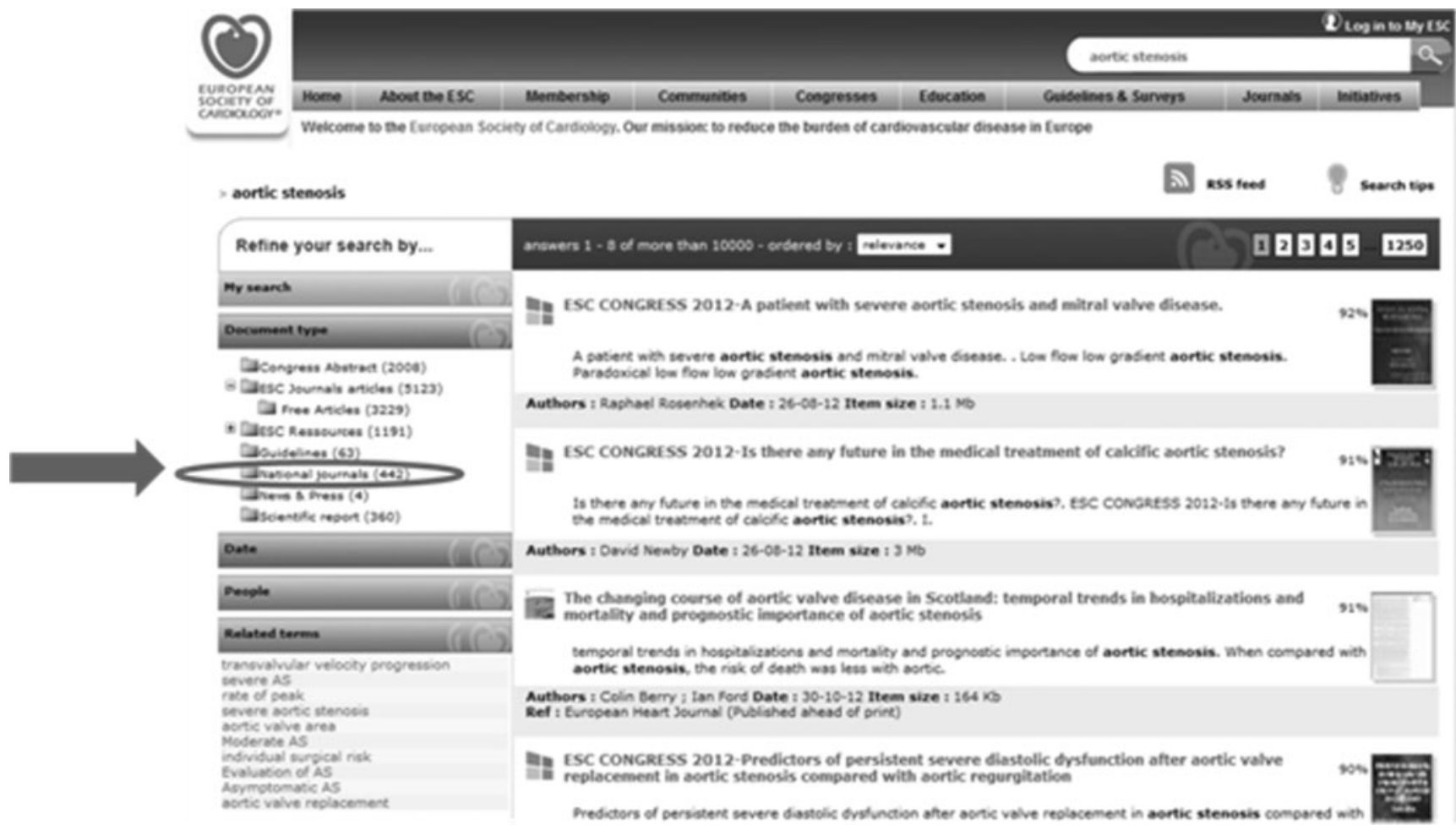

Fig. 2 Results page with relevant information about the documents found. On the left, there is a toolbar with a filtering system to refine the search 
Acknowledgments We are grateful for the support and assistance of Iris Chapuis, Isabelle Collin and Muriel Mioulet from the ESC National Cardiac Societies Relations Department at Heart House.

This is a joint simultaneous publication initiative involving all interested National Society Cardiovascular Journals of the European Society of Cardiology.

\section{Competing interests None}

\section{Funding None}

Open Access This article is distributed under the terms of the Creative Commons Attribution License which permits any use, distribution, and reproduction in any medium, provided the original author(s) and the source are credited.

\section{References}

1. Alfonso F, Ambrosio G, Pinto FJ, et al. European National Society cardiovascular journals. Background, rationale and mission statement of the "Editors' Club" (Task Force of the European Society of Cardiology). Heart. 2008;94:e19.

2. Alfonso F, Ambrosio G, Pinto FJ, et al. Editors' Network ESC Task Force. European Society of Cardiology national cardiovascular journals: the 'editors' network'. Eur Heart J. 2010;31:26-8.

3. Alfonso F, Timmis A, Pinto FJ, et al. Editors' Network European Society of Cardiology Task Force. Conflict of interest policies and disclosure requirements among European Society of Cardiology National Cardiovascular Journals. Eur Heart J. 2012;33:587-94.

4. Mills P, Timmis A, Huber K, et al. The role of European national journals in education. Heart. 2009;95:e3.

5. Timmis AD, Alfonso F, Ambrosio G, et al. Editors' Network. National society cardiovascular journals of Europe: Almanac 2011. Heart. 2011;97:1819.

6. Alfonso F, Bermejo J, Segovia J. Impactology, impactitis, impactotherapy. Rev Esp Cardiol. 2005;58:1239-45.

7. Bjork B-C, Welling P, Laakso M, et al. Open access to the scientific journal literature: situation 2009. PLoS ONE. 2010;5:e11273.

8. Van Aalst J. Using Google Scholar to estimate the impact of journal articles in education. Educ Res. 2010;39:387-400.

9. Falagas ME, Pitsouni EI, Malietzis GA, et al. Comparison of PubMed, scopus, web of science, and google scholar: strengths and weaknesses. FASEB J. 2008;22:338-42.

10. Kulkarni AV, Aziz B, Shams I, et al. Comparisons of citations in Web of Science, Scopus, and Google Scholar for articles published in general medical journals. JAMA. 2009;302:1092-6.

11. Alfonso F. The long pilgrimage of Spanish biomedical journals toward excellence. Who helps? Quality, impact and research merit. Endocrinol Nutr. 2010;57:110-20.

12. Merton RK. The Matthew effect in science. The reward and communication systems of science are considered. Science. 1968; 159:56-63.

13. Brody T, Harnad S, Carr L. Earlier Web usage statistics as predictors of later citation impact. J Am Soc Inform Sci Technol. 2006;57: 1060-72.14.

14. Perneger TV. Relation between online 'hit counts' and subsequent citations: prospective study of research papers in the BMJ. BMJ. 2004;329:546-7.

15. Wren JD. URL decay in MEDLINE: a 4-year follow-up study. Bioinformatics. 2008;24:1381-5.

16. Butler D. Web usage data outline map of knowledge. Nature. 2009;458:135.
17. Citrome L, Moss SV, Graf C. How to search and harvest the medical literature: let the citations come to you, and how to proceed when they do. Int J Clin Pract. 2009;63:1565-70.

18. Hrynaszkiewicz I, Norton ML, Vickers AJ, et al. Preparing raw clinical data for publication: guidance for journal editors, authors and peer reviwers. BMJ. 2010;340:c181.

19. Ross JS, Lehman R, Gross CP. The importance of clinical trial data sharing. Towards more open science. Circ Cardiovasc Qual Outcomes. 2012;5:238-40.

20. Piwowar HA, Day RS, Fridsma DB. Sharing detailed research data is associated with increased citation rate. PLoS ONE. 2007;2:e308.

21. Santoro E, Caldarola P, Villella A. Using Web 2.0 technologies and social media for the cardiologist's education and update. G Ital Cardiol (Rome). 2011;12:174-81.

22. Chatterjee P, Biswas T. Blogs and Twitter in medical publications: too unreliable to quote, or a change waiting to happen? S Afr Med J. 2011;101:712-4.

23. Chan XH, Wynn-Jones W. Time for open access secure online data collection tool. BMJ. 2012;11:49.

24. Masic I, Sivic S, Pandza H. Social Networks in medical education in Bosnia and Herzegovina. Mater Sociomed. 2012;24:162-4.

25. Nallamothu BK, Lüscher TF. Moving from impact to influence: measurement and the changing role of medical journals. Eur Heart J. 2012;33:2892-6.

26. Heras M, Avanzas P, Bayes-Genis A, et al. 2011 Annual summary. Another meeting with our readers. Rev Esp Cardiol. 2011;64:1207-14.

27. Meneghini R, Packer AL. Is there science beyond English? Initiatives to increase the quality and visibility of non-English publications might help to break down language barriers in scientific communication. EMBO Rep. 2007;8:112-16.

28. Carroll MW. Why full open access matters. PLoS Biol. 2011;9: e101210.

29. Bjork BC. A study of innovative features in scholarly open access journals. J Med internet Res. 2011;13:e115.

30. Alfonso F, Almonte K, Arai K, et al. Ibero-American cardiovascular journals. Proposals for a much-needed cooperation. Rev Esp Cardiol. 2009;62:1060-7.

31. Suber P. Ensuring open access for publicly funded research. BMJ. 2012;345:e5184.

32. Whitfield J. Open access comes of age. Nature. 2011;474:428.

33. Eysenbach G. Citation advantage of open access articles. PLoS Biol. 2006;4:e157.

34. Norris M, Oppenheim C, Rowland F. The citation advantage of openaccess articles. J Am Soc Inform Sci Technol. 2008;59:1963-72.

35. Evans JE, Reimer J. Open access and global participation in science. Science. 2009;323:1025.

36. Mueller PS, Murali NS, Cha SS, et al. The effect of online status on the impact factors of general internal medicine journals. Neth J Med. 2006;64:39-44

37. Murali NS, Murali HR, Auethavekiat P, et al. Impact of FUTON and NAA bias on visibility of research. Mayo Clin Proc. 2004;79:1001-6.

38. Gargouri Y, Hajjem C, Larivière V, et al. Self-selected or mandated, open access increases citation impact for higher quality research. PLoS ONE. 2010;5:e13636.

39. Davis PM. Open access, readership, citations: a randomized controlled trial of scientific journal publishing. FASEB J. 2011;25:2129-34.

40. Crum JA. An availability study of electronic articles in an academic health sciences library. J Med Libr Assoc. 2011;99:290-6.

41. Manikandan S, Vani NI. Restricting access to publications from funded research: ethical issues and solutions. J Postgrad Med. 2010;56:154-6.

42. Hawkes N. UK government comes down in favor of making all publicly funded research "open access". BMJ. 2012;345:e4878.

43. Noorden RV. Europe joins UK open-access bid. Britain plans to dip in to research funding to pay for results to be freely available. Nature. 2012;487:285. 